\title{
Economic abuse and its associations with symptoms of common mental disorders among women in a cross-sectional survey in informal settlements in Mumbai, India
}

Suman Kanougiya ${ }^{1,2}$, Nayreen Daruwalla', Lu Gram³ ${ }^{3}$ Apoorwa Deepak Gupta', Muthusamy Sivakami ${ }^{2}$ and David Osrin ${ }^{3 *}$

\begin{abstract}
Background: Domestic violence takes a range of interconnected forms, of which economic abuse is common, but less studied than others. We examine the prevalence of economic abuse, its determinants, and its association with symptoms of depression, anxiety, and suicidal ideation.

Methods: Our cross-sectional survey in informal settlement areas in Mumbai, India, asked women aged 18-49 years 15 questions about acquisition, use, and maintenance of economic resources, demographic and socioeconomic factors, and physical, sexual, and emotional violence. We administered the Patient Health Questionnaire 9 (PHQ-9) and Generalised Anxiety Disorder 7 (GAD-7) scales and asked about suicidal thinking. Determinants of economic abuse and its associations with positive screens for depression and anxiety were explored in univariable and multivariable logistic regression models.

Results: Of 4906 ever-married women respondents, 23\% reported at least one form of economic abuse by either an intimate partner or another family member. The commonest were denial of property rights (10\%), not being trusted with money (8\%), and coercive appropriation of belongings (7\%). Economic abuse was more commonly reported by widowed, separated, or divorced women than by married women (aOR 12.4; 95\% Cl 6.4, 24.1), and when their partners used alcohol or drugs (aOR 1.4; 95\% Cl 1.2-1.7). Women had greater odds of reporting economic abuse if they had suffered emotional (aOR 6.3; 95\% Cl 5.0-7.9), physical (aOR 1.9; 95\% Cl 1.4-2.6), or sexual violence (aOR 5.4; 95\% Cl 3.6-8.1) in the preceding 12 months. Economic abuse was independently associated with positive screens for moderate-severe depression (aOR 2.6; 95\% Cl 2.0-3.4), anxiety (aOR 2.7; 95\% Cl 1.9-3.8), and suicidal ideation (aOR 2.2; 95\% Cl 1.5-3.1). The odds of anxiety and depression increased with each additional form of economic abuse.

(Continued on next page)
\end{abstract}

\footnotetext{
* Correspondence: d.osrin@ucl.ac.uk

${ }^{3}$ Institute for Global Health, University College London, London WC1N IEH,

UK

Full list of author information is available at the end of the article
}

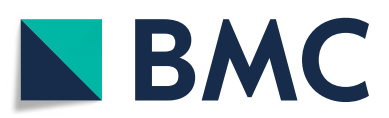

(c) The Author(s). 2021 Open Access This article is licensed under a Creative Commons Attribution 4.0 International License, which permits use, sharing, adaptation, distribution and reproduction in any medium or format, as long as you give appropriate credit to the original author(s) and the source, provide a link to the Creative Commons licence, and indicate if changes were made. The images or other third party material in this article are included in the article's Creative Commons licence, unless indicated otherwise in a credit line to the material. If material is not included in the article's Creative Commons licence and your intended use is not permitted by statutory regulation or exceeds the permitted use, you will need to obtain permission directly from the copyright holder. To view a copy of this licence, visit http://creativecommons.org/licenses/by/4.0/ The Creative Commons Public Domain Dedication waiver (http://creativecommons.org/publicdomain/zero/1.0/) applies to the data made available in this article, unless otherwise stated in a credit line to the data. 
(Continued from previous page)

Discussion: To our knowledge, this is the first community-based study in India of the prevalence of economic abuse and its associations with symptoms of common mental disorders. It provides empirical support for the idea that economic abuse is at least as harmful to women's mental health as physical violence. Surveys should include questions on economic abuse and prevention and intervention strategies need to help survivors to understand its forms.

Keywords: Economic abuse, Domestic violence, Common mental disorders, Depression, Anxiety, Suicidal ideation, India

\section{Background}

Violence against women occurs across all regions, societies, and cultures [1]. It is a serious public health concern which affects the physical [2], reproductive [3], mental $[4,5]$, and social wellbeing of more than onethird of women [6]. It is also widely underreported [7]. Domestic violence takes a range of forms. The most often measured are physical and sexual violence [8,9], but the importance of emotional or psychological violence as an insidious cause of harm to women's wellbeing is becoming apparent [10, 11]. Global considerations have focused on intimate partner violence, a form of domestic violence described as "any behaviour by a current or former male intimate partner within the context of marriage, cohabitation or any other formal or informal union, that causes physical, sexual or psychological harm" [6]. In South Asia, considerations of violence by perpetrators within the family extend beyond intimate partners [12], not only to sexual violence by perpetrators other than partners $[6,13]$, but to forms of violence perpetrated by other family members. India's Protection of Women from Domestic Violence Act, 2005, defines domestic violence as occurring within a domestic relationship: "a relationship between two persons who live or have, at any point of time, lived together in a shared household, when they are related by consanguinity, marriage, or through a relationship in the nature of marriage, adoption or are family members living together as a joint family." [14].

Domestic violence is therefore a composite of intimate partner violence and violence by others in the context of the home. We follow this broader definition in considering economic abuse [9], a means of power and control within domestic relationships [15] whose dimensions have recently gained attention $[16,17]$. Economic abuse overlaps with emotional violence in its use of coercive control [18-20], but is increasingly recognised as a category of violence in itself $[21,22]$. Its reduction is essential to achieving at least five of the 17 United Nations Sustainable Development Goals.

A developing consensus defines economic abuse as control over a person's ability to obtain, use, or sustain access to economic resources in a manner which diminishes the victim's capacity to support herself, threatens her economic security and potential for self-sufficiency, or forces her to depend on perpetrators financially [21, $23,24]$. The definition admits a broad range of economic acts; for example, preventing access to property, disrupting employment (preventing employment outside the home or preventing an employed person from achieving their working hours $[25,26])$, depleting savings and assets or generating expenditure and debt [25], controlling or destroying money and resources, and eviction from the home. Limiting the survivor's access to resources creates a vicious circle in which their capacity to change the abusive situation is compromised [27, 28].

Estimates of prevalence vary with location, source, and methods [29]. Most estimates of lifetime prevalence of economic abuse come from high-income countries: 3$5 \%$ in Canada from police reports and a social survey [30, 31], 15\% from a survey in Australia [32], 12-15\% from cohort studies in the United States [18, 33, 34], and $21 \%$ from a nationally representative survey in the United Kingdom [35]. Estimates in middle-income settings include $7 \%$ from a Demographic and Health Survey in the Philippines [36], 28\% from a village census in Vietnam [37], 45\% from national surveys among Palestinian women [38], and $62 \%$ in a survey in rural Bangladesh [29].

India is a signatory to the Convention on the Elimination of all Forms of Discrimination Against Women and the International Covenant on Economic, Social, and Cultural Rights. India's Protection of Women from Domestic Violence Act, 2005 aims to protect women's rights guaranteed under the constitution and applies to violence of any kind occurring within the family. It characterises economic abuse as a form of domestic violence, an advance given that it is often not considered or recognised beyond dowry violence [39]. Studies on economic abuse in India have reported lifetime prevalence ranging from $10 \%$ in a community-based study in Haryana [40], 11\% among both men and women attending a general hospital in Gujarat [41], 37\% among women outpatients at an Urban Health Centre in Punjab [42], and $89 \%$ in a four-site study [43].

Economic abuse reduces employment opportunities and stability, diminishes resources for survival such as housing and money, lowers the standard of living, adversely affects childcare and social capital and diminishes economic self-sufficiency and self-efficacy. Marital 
dependency and Interdependence theories suggest that women are financially, educationally, and occupationally dependent on their male partners. Economic dependence is a significant obstacle for a woman who wishes to leave an abusive partner and limits her ability to end a violent relationship. Women who escape such relationships are often impoverished, and economic abuse may continue even after they have left. Economic and interpersonal relationship difficulties are associated with the development of depression and anxiety, and suicidal ideation [5, 44-50]. Women who experience economic abuse may suffer similar mental health consequences to those caused by violent abuse, although the link between economic abuse and common mental disorders has not been well identified $[17,25,51,52]$.

Three aspects of economic abuse of women have gained attention in recent years: the need to measure it [16], the need to understand its prevalence $[16,53]$, and the need to understand its effects on women's mental health $[17,50]$. There have been few studies of the association between economic abuse and common mental disorder, and none in India [34]. We aimed, therefore, to examine the prevalence of economic abuse, its determinants, and its association with symptoms of depression, anxiety, and suicidal ideation in informal settlements in Mumbai.

\section{Methods}

\section{Setting}

Urban informal settlements are characterised by overcrowding and unsanitary and unhealthy living conditions [54]. Residents face insecure tenure, limited safe drinking water, sanitation, drainage, and solid waste management, poor internal and approach roads, limited street lighting, and poor quality of shelter [55]. Data for our study come from a survey done before implementing a community-based intervention to address violence against women in informal settlements in Mumbai [56]. The non-government organisation SNEHA (Society for Nutrition, Education and Health Action) has run a program focusing on primary, secondary, and tertiary prevention of violence for 20 years. The primary beneficiaries of the program are residents of informal settlements. Primary prevention is addressed through a combination of community group activities and resulting individual voluntarism. Secondary prevention includes local crisis response and psychological first aid by community organisers and referral to centres which provide counselling, legal, and psychotherapeutic support, with links to the police and medical, shelter, and social service providers. Tertiary prevention is provided primarily through referral to psychiatric and legal services.

\section{Design}

Data come from a cross-sectional systematic random sample survey in 50 equally-sized clusters of roughly 500 residential households in two large informal settlement areas. From a random starting point in each cluster, alternate households were enumerated without replacement until we had collected information from 100 women aged 18-49 years. When more than one potential respondent was available in a household, an algorithm led the investigators to select the youngest disabled, youngest married, or youngest unmarried woman. We did this to ensure representation of younger married women with disability who may be more vulnerable to domestic violence [57].

\section{Data collection}

Between 5th December 2017 and 28th March 2019, 5277 households were approached for the survey. A fuller description of data collection is available elsewhere [58]. Briefly, 16 women interviewers with graduate education and 3 months of training mapped the study areas and enumerated household residents. After explaining the study, interviewers allowed women time to consider participation. They were supported by three field supervisors with a direct linkage to counselling services, available by phone at any time. In order to maintain privacy, interviews were arranged by advance appointment and avoided times when partners or children were likely to return from work or school. Women were interviewed at home or in a local community office if they preferred it. The interview began with general questions about demography, household residents, education, socioeconomic position, maternity, and health. If a family member, neighbour, or friend entered, the interviewer went back to asking questions about general health. If the person showed signs of staying, the interview was terminated and completed over up to three repeat visits. Gatekeepers and community members were briefed that SNEHA had planned to start work on violence against women in these areas and not only collect data. This would eventually help the families residing in these communities. As a result of the gatekeeper consent process, community members were aware that interviewers would be visiting people in their area and this limited intrusion. Interviewers used electronic tablets to enter information in a database in CommCare (www.dimagi.com).

\section{Variables}

We used existing Hindi versions of scales where possible. If not, they were translated from English, piloted in two clusters external to the trial, amended, and backtranslated. We screened for depression with the Patient Health Questionnaire 9 (PHQ-9) questionnaire [59] and anxiety with the Generalised Anxiety Disorder 7 (GAD7) questionnaire $[60,61]$. For both screens, questions referred to the last 2 weeks and each item was coded 0 
(not at all), 1 (several days), 2 (more than half the days), or 3 (nearly every day). Both of these questionnaires are established and recommended in mental health research in India. A version of the PHQ-9 has been validated in 11 Indian languages [62], but local validation studies of the GAD-7 have been limited [63-66]. Our analyses used binary variables describing moderate or severe symptoms of depression and anxiety. A PHQ-9 score of 10-27 was taken as suggesting at least moderate depression [67], and a GAD-7 score of 10-21 as suggesting at least moderate anxiety. We asked two questions about suicidality: "In the past 12 months, did you ever consider attempting suicide?" and "in the past 12 months, did you ever attempt suicide?" [68]. Our analyses used a binary composite of both questions.

We asked respondents about their experience of violence perpetrated by intimate partners or other family members. We described the experience of economic abuse with binary responses to 15 individual questions based on programme experience in supporting survivors of violence, augmented by four focus group discussions with counsellors, community actors, and lawyers. Questions covered, over a woman's lifetime, (1) denying her the right to property, (2) coercive appropriation of her belongings or (3) money or use of her bank account, (4) convincing her to make a loan that was not repaid, (5) selling her valuables without consent, (6) lying to her about employment or finances, (7) harassing her for not bringing natal money or property into the marital family or (8) coercing her to do so, (9) preventing her from seeking employment, (10) hiding money from her, (11) taking a loan without her consent, (12) gambling without her consent, (13) not trusting her with money, (14) keeping from having enough money, and (15) coercing her to hand over her income. The answers to each these questions could apply to either an intimate partner or another domestic perpetrator. They map onto an Economic Coercion Scale recently developed from work in Bangladesh, which includes 36 questions representing two domains: interference in acquisition of economic resources and interference in the use or maintenance of economic resources [29]. We summed these responses to generate a composite score describing the intensity of economic abuse, with values from 0 to 15 .

Emotional violence was described by five questions, physical violence by nine, and sexual violence by four [58]. Women's affirmative response to any of these questions-lifetime or past year-was described by a binary composite of physical violence, sexual violence, and emotional violence. Marital status was described by a categorical binary variable distinguishing married respondents from respondents who had been widowed, separated, or divorced. Socioeconomic position was described by quintiles of a standardised score derived from the first component of a principal components analysis of the ownership of 22 assets $[69,70]$.

Cronbach's alpha indicated internal consistency for the PHQ-9 ( $\alpha$ 0.86), GAD-7 ( $\alpha$ 0.84), 15 -items on economic abuse $(\alpha 0.86)$, nine items on physical abuse $(\alpha 0.83)$, four items on sexual abuse ( $\alpha$ 0.76), and five items on emotional abuse ( $\alpha$ 0.82).

\section{Sample size}

Completion of 100 questionnaires in each of 50 clusters would yield a total sample of 5000. An estimate of prevalence from a cross-sectional sample of 4900 evermarried women in a population of 125,000 would have a precision of $\sim 1-1.5 \%$. Within this, and assuming a conservative intracluster correlation coefficient of 0.05 , a comparison of two categories of a determinant for 100 respondents in each of 50 clusters would provide $80 \%$ power to detect a difference of $6 \%$ in prevalence estimates of $10-20 \%$.

\section{Statistical analysis}

We tabulated frequencies and proportions of demographic and socioeconomic variables, responses to questions about economic abuse, lifetime and 12-month experience of physical, sexual, and emotional violence, and depression, anxiety, and suicidal thoughts and action. We used cross-tabulation to examine associations between economic abuse, demographic and socioeconomic characteristics, and other forms of violence. We assessed the determinants of economic abuse in univariable and multivariable logistic regression models. We then examined the association of symptoms of common mental disorders with economic abuse in a series of univariable and multivariable logistic regression models with moderate or severe depression, moderate or severe anxiety, and suicidal thoughts or action in the last 12 months as dependent variables. Unadjusted models included economic abuse, emotional, physical, and sexual violence as exposures, followed by two adjusted models: the first including covariates for respondent age, education, religion, caste, socioeconomic asset quintile, respondent and husband employment, and respondent and husband drug or alcohol use, and the second adjusted for the same variables and also for other forms of violence. Finally, we examined the effect of increasing numbers of forms of economic abuse on moderate or severe depression, moderate or severe anxiety, and suicidal thoughts or action in the last 12 months. We adjusted the logistic regression models in the same way as above and then predicted marginal effects to illustrate the increase in the proportion of women with symptoms of common mental disorders for each unit increase in acts of economic abuse from 0 to 15 . We modelled the logodds of a positive screen for moderate or severe 
Table 1 Characteristics of 4906 ever-married women in informal settlements in Mumbai

\begin{tabular}{|c|c|c|c|c|c|}
\hline & Frequency & (\%) & & Frequency & $(\%)$ \\
\hline Marital status & & & 4 & 933 & $(20)$ \\
\hline Currently married & 4694 & (96) & 5 least poor & 935 & $(20)$ \\
\hline Widowed, separated, or divorced & 212 & (4) & Respondent uses alcohol or drugs & 612 & $(12)$ \\
\hline Respondent age (years) & & & Husband age (years) & & \\
\hline $18-25$ & 1025 & $(21)$ & $18-19$ & 14 & $(<1)$ \\
\hline $26-30$ & 1421 & $(29)$ & $20-29$ & 917 & (19) \\
\hline $31-36$ & 1172 & $(24)$ & $30-39$ & 2102 & $(44)$ \\
\hline $37-49$ & 1288 & $(26)$ & $40-49$ & 1370 & $(29)$ \\
\hline Respondent education (school years) & & & $50+$ & 391 & (8) \\
\hline No education & 938 & (19) & Husband in remunerated work & 4686 & (98) \\
\hline Primary $1-5$ & 846 & $(17)$ & Husband monthly income (Indian Rupees) & & \\
\hline Middle 6-8 & 1099 & $(22)$ & $<10,000$ & 1095 & $(24)$ \\
\hline High 9-10 & 1105 & (23) & $10,000-11,999$ & 997 & (21) \\
\hline Senior $11-12$ & 533 & $(11)$ & $12,000-14,999$ & 652 & (14) \\
\hline Above 12 & 385 & (8) & $15,000+$ & 1942 & (41) \\
\hline Children & & & Husband uses alcohol or drugs & 2100 & (44) \\
\hline 0 & 8 & $(<1)$ & All & 4906 & (100) \\
\hline
\end{tabular}

12950

21666

31040

$4+\quad 704$

Respondent in remunerated work $\quad 1182$

Respondent monthly income (Indian Rupees)

$\begin{array}{ll}<1000 & 233 \\ 1000-2999 & 303 \\ 3000-5999 & 279 \\ 6000+ & 322\end{array}$

Religion

Hindu

Muslim

1826

Other

Housing type

Kachha (insubstantial) 336

Pukka (robust)

Mixed

Toilet type

Private

Public

Open defecation

2

Socioeconomic quintile

1 poorest

$\begin{array}{ll}1 \text { poorest } & 969 \\ 2 & 936 \\ 3 & 934\end{array}$

Table 1 Characteristics of 4906 ever-married women in informal settlements in Mumbai (Continued)

common mental disorder as a step function from 0 to 1 act of economic abuse, followed by a linear increase from 1 to 15 acts. We tested for non-linearity by fitting a quadratic term for the increase from 1 to 15 . The analysis was carried out in STATA 15.0 (StataCorp LLC), and all estimates were adjusted for survey design.

\section{Results}

Table 1 summarises characteristics of 4906 ever-married women respondents. Around 19\% had had no schooling, and $38 \%$ had reached middle school. A quarter of women were in remunerated work-although $20 \%$ of these women earned less than INR 12,000 a year (USD 163) - and 98\% of their partners were in remunerated work with a mean annual income of INR 172,383 (USD 2335). More than half identified as Hindu and of general caste. $12 \%$ said that they used alcohol or drugs, compared with $44 \%$ of their husbands.

Table 2 summarises the prevalence of economic abuse, domestic violence, and screening for common mental disorders. Overall, $23 \%$ of women reported experiencing at least one of the 15 forms of economic abuse, with no missing observations. The commonest were that their property rights had been denied, or that belongings had been taken from them. Forms of violence other than economic abuse were also common, the commonest being emotional violence. Overall, 9\% of women screened positive for moderate or severe depressive symptoms on the PHQ-9, 6\% for anxiety on the GAD-7, and 6\% had contemplated or attempted suicide in the last year. 
Table 2 Prevalence of economic abuse, domestic violence, and symptoms of common mental disorder among 4906 evermarried women in informal settlements in Mumbai

n

(\%)

\begin{tabular}{|c|c|c|}
\hline \multicolumn{3}{|l|}{ Lifetime economic abuse } \\
\hline Denied the right to property & 488 & (10) \\
\hline Not trusted with money & 394 & (8) \\
\hline Belongings taken by force & 330 & (7) \\
\hline Money hidden from respondent & 277 & (6) \\
\hline Told lies about job or finances & 263 & (5) \\
\hline Convinced to loan money and not repaid & 255 & (5) \\
\hline Valuables sold without consent & 243 & (5) \\
\hline Kept from having enough money & 230 & (5) \\
\hline $\begin{array}{l}\text { Harassed for not bringing natal family money or } \\
\text { property }\end{array}$ & 222 & (4) \\
\hline Prevented from seeking employment & 160 & (3) \\
\hline Money taken or bank account used coercively & 122 & (2) \\
\hline Forced to bring money from natal family & 110 & (2) \\
\hline Forced to hand over income & 100 & (2) \\
\hline Gambling without her consent & 92 & (2) \\
\hline Loan taken without her consent & 45 & (1) \\
\hline Any of the above & 1106 & (23) \\
\hline \multicolumn{3}{|l|}{ Lifetime domestic violence } \\
\hline Physical violence & 1243 & (25) \\
\hline Sexual violence & 285 & (6) \\
\hline emotional violence & 1553 & (32) \\
\hline \multicolumn{3}{|l|}{ Domestic violence in last 12 months } \\
\hline Physical violence & 618 & (13) \\
\hline Sexual violence & 186 & (4) \\
\hline Emotional violence & 927 & (19) \\
\hline \multicolumn{3}{|l|}{ Symptoms of common mental disorders } \\
\hline Moderate or severe depression on PHQ-9 & 443 & (9) \\
\hline Moderate or severe anxiety on GAD-7 & 299 & (6) \\
\hline Suicidal thoughts in the past 12 months & 310 & (6) \\
\hline Suicidal action in the past 12 months & 31 & $(<1)$ \\
\hline Suicidal thoughts or action in the past 12 months & 314 & (6) \\
\hline All & 4906 & $(100)$ \\
\hline
\end{tabular}

PHQ-9 Patient Health Questionnaire 9-question screen, GAD-7 Generalised Anxiety Disorder 7-question screen

Table 3 shows crude and adjusted associations between sociodemographic determinants and economic abuse. Economic abuse was more commonly reported by widowed, separated, or divorced women than by married women (aOR 12.4; 95\% CI 6.4, 24.1). In adjusted analyses, no clear evidence for a difference in the prevalence of economic abuse was found by age, education, religion, or socioeconomic position, although greater odds were seen for women in remunerated work. Economic abuse was more likely to be reported when husbands used alcohol or drugs $(1.2 ; 1.0,1.6)$. In sensitivity analyses, husbands' use of alcohol or drugs and women's employment status did not alter the adjusted estimates. Women were more likely to have experienced economic abuse if they had suffered emotional (aOR 6.3; 95\% CI 5.0, 7.9), physical $(1.9 ; 1.4,2.6)$, or sexual violence $(5.4 ; 3.6,8.1)$ in the preceding 12 months.

Table 4 shows the associations between economic abuse and screens for depression, anxiety, and suicidal thoughts or actions. Three odds ratios are presented: a crude odds ratio derived from a univariable logistic regression model, an adjusted odds ratio from a multivariable model including sociodemographic covariates, and a further model adjusted with both sociodemographic covariates and covariates describing the other three forms of violence. In the fully adjusted model, economic abuse was associated independently with more than a doubling of the odds of screening positive for moderate or severe depression or anxiety. Physical and sexual violence were associated independently with a 1.5-fold increase in odds. Similar findings were seen for anxiety, and the odds of suicidal thinking or action were more than doubled.

Figure 1 presents the findings from conditional logistic regression models for the impact of economic abuse on positive screens for depression, anxiety, and suicidal ideation. For each outcome, predicted marginal effects are presented for three models: crude, adjusted with sociodemographic covariates, and adjusted with both sociodemographic covariates and covariates describing the three other forms of violence. In the absence of economic abuse, the predicted proportion of women with depression was $5 \%$, with anxiety $3 \%$, and with suicidal thoughts or action $3 \%$. These proportions increased as women reported additional indicators. When women reported 15 indicators of economic abuse, the predicted proportion with depression was $87 \% \%$ in the crude model (61\% in the second adjusted model), with anxiety $76 \%$ (44\%), and with suicidal thoughts or action $71 \%$ (28\%). We found no evidence for non-linearity $(p>0.05)$.

\section{Discussion \\ Key findings}

In our survey of over 4900 ever-married women aged $18-49$ years in informal settlements, $23 \%$ had experienced at least one form of economic abuse in their lifetime. The odds of economic abuse were greater when partners used alcohol or drugs and were two-to-five times greater when concurrent emotional, physical, or sexual violence was present. We found little evidence of association with other sociodemographic predictors. Economic abuse was associated with a doubling of reported symptoms of depression, anxiety, and suicidal 
Table 3 Associations of sociodemographic characteristics with economic abuse, for 4906 ever-married women in informal settlements in Mumbai

\begin{tabular}{|c|c|c|c|c|c|c|c|c|}
\hline & \multicolumn{4}{|c|}{ Economic Abuse } & \multirow[b]{3}{*}{ OR } & \multirow[b]{3}{*}{$(95 \% \mathrm{Cl})$} & \multirow[b]{3}{*}{$\mathrm{aOR}$} & \multirow[b]{3}{*}{$(95 \% \mathrm{Cl})$} \\
\hline & \multicolumn{2}{|l|}{ No } & \multicolumn{2}{|l|}{ Yes } & & & & \\
\hline & $n$ & $(\%)$ & $n$ & $(\%)$ & & & & \\
\hline \multicolumn{9}{|l|}{ Marital status } \\
\hline Currently married & 3710 & $(79)$ & 984 & $(21)$ & 1 & & 1 & \\
\hline Widowed, separated, divorced & 90 & $(42)$ & 122 & $(58)$ & 5.1 & $(3.7,7.1)$ & 12.4 & $(6.4,24.1)$ \\
\hline \multicolumn{9}{|l|}{ Respondent age (years) } \\
\hline $18-25$ & 804 & (78) & 221 & $(22)$ & 1 & & 1 & \\
\hline $26-30$ & 1106 & (78) & 315 & $(22)$ & 1.0 & $(0.8,1.3)$ & 1.2 & $(0.9,1.7)$ \\
\hline $31-36$ & 915 & $(78)$ & 257 & $(22)$ & 1.0 & $(0.8,1.3)$ & 1.2 & $(0.9,1.6)$ \\
\hline $37-49$ & 975 & $(76)$ & 313 & $(24)$ & 1.2 & $(0.9,1.5)$ & 1.5 & $(1.1,2.1)$ \\
\hline \multicolumn{9}{|l|}{ Respondent education (school years) } \\
\hline No education & 726 & $(77)$ & 212 & $(23)$ & 1 & & 1 & \\
\hline Primary $1-5$ & 653 & $(77)$ & 193 & $(23)$ & 1.0 & $(0.8,1.3)$ & 0.8 & $(0.6,1.1)$ \\
\hline Middle 6-8 & 830 & $(76)$ & 269 & $(24)$ & 1.1 & $(0.9,1.4)$ & 0.9 & $(0.7,1.1)$ \\
\hline High 9-10 & 844 & $(76)$ & 261 & $(24)$ & 1.1 & $(0.9,1.3)$ & 1.0 & $(0.8,1.3)$ \\
\hline Senior $11-12$ & 433 & $(81)$ & 100 & (19) & 0.8 & $(0.6,1.1)$ & 0.8 & $(0.6,1.4)$ \\
\hline Above 12 & 314 & $(82)$ & 71 & (18) & 0.8 & $(0.6,1.1)$ & 0.9 & $(0.6,1.3)$ \\
\hline \multicolumn{9}{|l|}{ Religion } \\
\hline Muslim & 1403 & $(77)$ & 423 & $(23)$ & 1 & & 1 & \\
\hline Hindu & 2255 & (78) & 627 & $(22)$ & 0.9 & $(0.8,1.1)$ & 1.1 & $(0.9,1.3)$ \\
\hline Other & 142 & $(72)$ & 56 & $(28)$ & 1.3 & $(0.9,1.8)$ & 0.7 & $(0.4,1.1)$ \\
\hline \multicolumn{9}{|l|}{ Caste } \\
\hline General & 2233 & (78) & 621 & $(22)$ & 1 & & 1 & \\
\hline Other backward caste & 942 & $(80)$ & 238 & $(20)$ & 0.9 & $(0.8,1.1)$ & 0.8 & $(0.7,0.9)$ \\
\hline Scheduled tribe or caste & 625 & $(72)$ & 247 & $(28)$ & 1.4 & $(1.2,1.7)$ & 1.3 & $(1.0,1.6)$ \\
\hline \multicolumn{9}{|l|}{ Socioeconomic quintile } \\
\hline 1 poorest & 717 & $(74)$ & 252 & $(26)$ & 1 & & 1 & \\
\hline 2 & 727 & (78) & 209 & $(22)$ & 0.8 & $(0.7,1.0)$ & 0.9 & $(0.7,1.1)$ \\
\hline 3 & 720 & $(77)$ & 214 & $(23)$ & 0.9 & $(0.8,1.0)$ & 0.9 & $(0.7,1.2)$ \\
\hline 4 & 727 & (78) & 206 & $(22)$ & 0.8 & $(0.6,1.0)$ & 0.8 & $(0.6,1.1)$ \\
\hline 5 least poor & 765 & $(82)$ & 170 & (18) & 0.6 & $(0.5,0.8)$ & 0.7 & $(0.5,0.9)$ \\
\hline \multicolumn{9}{|l|}{ Respondent in remunerated work } \\
\hline No & 2982 & $(80)$ & 742 & $(20)$ & 1 & & 1 & \\
\hline Yes & 818 & $(69)$ & 364 & $(31)$ & 1.8 & $(1.5,2.1)$ & 1.4 & $(1.2,1.7)$ \\
\hline \multicolumn{9}{|l|}{ Husband in remunerated work } \\
\hline No & 51 & $(52)$ & 48 & $(48)$ & 1 & & 1 & \\
\hline Yes & 3674 & (78) & 1012 & $(22)$ & 0.3 & $(0.2,0.5)$ & 0.7 & $(0.4,1.3)$ \\
\hline \multicolumn{9}{|l|}{ Respondent uses alcohol or drugs } \\
\hline No & 3393 & $(79)$ & 901 & $(21)$ & 1 & & 1 & \\
\hline Yes & 407 & $(67)$ & 205 & (34) & 1.9 & $(1.5,2.3)$ & 1.2 & $(1.0,1.6)$ \\
\hline \multicolumn{9}{|l|}{ Husband uses alcohol or drugs } \\
\hline No & 2240 & $(83)$ & 448 & $(17)$ & 1 & & 1 & \\
\hline Yes & 1485 & (71) & 615 & (29) & 2.1 & $(1.8,2.4)$ & 1.4 & $(1.2,1.7)$ \\
\hline
\end{tabular}


Table 3 Associations of sociodemographic characteristics with economic abuse, for 4906 ever-married women in informal settlements in Mumbai (Continued)

\begin{tabular}{|c|c|c|c|c|c|c|c|c|}
\hline & \multicolumn{4}{|c|}{ Economic Abuse } & \multirow[b]{3}{*}{ OR } & \multirow[b]{3}{*}{$(95 \% \mathrm{Cl})$} & \multirow[b]{3}{*}{ aOR } & \multirow[b]{3}{*}{$(95 \% \mathrm{Cl})$} \\
\hline & \multicolumn{2}{|l|}{ No } & \multicolumn{2}{|l|}{ Yes } & & & & \\
\hline & n & $(\%)$ & $\mathrm{n}$ & $(\%)$ & & & & \\
\hline \multicolumn{9}{|c|}{ Emotional violence in last 12 months } \\
\hline No & 3438 & (86) & 541 & (14) & 1 & & 1 & \\
\hline Yes & 362 & (39) & 565 & (61) & 9.9 & $(8.2,12.0)$ & 6.3 & $(5.0,7.9)$ \\
\hline \multicolumn{9}{|c|}{ Physical violence in last 12 months } \\
\hline No & 3548 & (83) & 740 & (17) & 1 & & 1 & \\
\hline Yes & 252 & $(41)$ & 366 & (59) & 7.0 & $(5.4,8.9)$ & 1.9 & $(1.4,2.6)$ \\
\hline \multicolumn{9}{|c|}{ Sexual violence in last 12 months } \\
\hline No & 3761 & $(80)$ & 959 & (20) & 1 & & 1 & \\
\hline Yes & 39 & (21) & 147 & (79) & 14.8 & $(10.3,21.1)$ & 5.4 & $(3.6,8.1)$ \\
\hline
\end{tabular}

ideation. The odds of a positive screen for moderate or severe common mental disorders increased with each additional form of economic abuse a woman suffered, a dose-response effect in terms of the breadth of economic abuse.

\section{Comparison with other studies}

To our knowledge, this is the first community-based study in India of the prevalence of economic abuse and its associations with symptoms of common mental disorders. Two strengths were the inclusion of abuse by family members other than intimate partners (important in our context), and the use of established scales to examine associations with mental health symptoms. The questions we used to identify economic abuse were similar to items used in other studies [27, 28, 71, 72], and our findings fell within the reported ranges from India [40-43] and other countries [18, 29, 33, 34]. Economic abuse rarely occurs in isolation and most women who reported it were more likely to report physical, sexual, or emotional abuse $[17,35]$. The prevalences of these forms of violence were consistent with previous studies in India [73-77]. In general, the prevalences of depression, anxiety, and suicidal thoughts were comparable with other community studies [78, 79].

\section{Determinants}

Women who were widowed, separated, or divorced were more likely to report experiences of economic abuse in their lifetime. Economic abuse may have contributed to their leaving the relationship: our data did not tell us whether the abuse occurred before or after the split. Nevertheless, past economic abuse can leave a lasting financial burden on survivors [19, 26]. For widowed women, denial of property rights and other means of financial support has been well described in India [80,
81], although age and socioeconomic position did not alter the odds of economic abuse. Women in remunerated employment were more likely to report economic violence than unremunerated women, in accordance with other studies in India which suggest that economic empowerment may not protect women from violence [82], and that violence may increase as partners attempt to compensate for women's enhanced status and independence associated with employment [83, 84]. Again, it is unclear whether seeking employment was a response to the pressures of a difficult home situation or whether employment increased harassment [85]. Economic abuse keeps women in poverty by reducing their access to independent livelihoods and compromising educational attainment and growth opportunities [26]. The combination of abuse and poverty may trap women in abusive relationships and narrow their focus to basic economic survival. Women's efforts to become less dependent on the family, or more self-sufficient, have been correlated with an escalation in the intensity and frequency of abuse [85]. The link between alcohol and drug use and domestic abuse is well known [86]. Dependency leads simultaneously to more expenditure on substances, less security of livelihood, and a focus on the availability of money for the user. Alcohol has far-reaching effects on all forms of violence and in initiating and sustaining aggressive behaviour [87].

The large odds ratios illustrated the fact that economic abuse is part of a broader pattern of domestic violence. Our study suggests that economic abuse co-occurred with physical, sexual, and emotional violence, contributing substantially to the totality of violence described recently in rural Bangladesh $[29,50]$. Of the 1106 women who reported economic abuse, 51\% had also suffered emotional, $13 \%$ sexual violence and $33 \%$ physical violence. Our finding that economic abuse was more common than physical abuse contrasts with other published estimates [22]. 
Table 4 Associations of economic, emotional, physical, and sexual violence against women with symptoms of depression, anxiety, and suicidal ideation, for 4906 ever-married women in informal settlements in Mumbai

\begin{tabular}{|c|c|c|c|c|c|c|c|c|c|c|}
\hline & No & $(\%)$ & Yes & (\%) & OR & $(95 \% \mathrm{Cl})$ & aOR1 & $(95 \% \mathrm{Cl})$ & aOR2 & $(95 \% \mathrm{Cl})$ \\
\hline \multicolumn{11}{|c|}{ Moderate or severe depression on PHQ-9 } \\
\hline \multicolumn{11}{|c|}{ Economic abuse } \\
\hline No & 3441 & $(95)$ & 165 & (5) & 1 & & 1 & & 1 & \\
\hline Yes & 1022 & $(79)$ & 278 & $(21)$ & 5.7 & $(4.5,7.1)$ & 4.4 & $(3.5,5.4)$ & 2.6 & $(2.0,3.4)$ \\
\hline \multicolumn{11}{|c|}{ Emotional violence in last $12 \mathrm{~m}$} \\
\hline No & 3759 & $(95)$ & 220 & $(5)$ & 1 & & 1 & & 1 & \\
\hline Yes & 704 & $(76)$ & 223 & $(24)$ & 5.4 & $(4.4,6.7)$ & 4.8 & $(3.9,6.0)$ & 2.5 & $(1.9,3.3)$ \\
\hline \multicolumn{11}{|c|}{ Physical violence in last $12 \mathrm{~m}$} \\
\hline No & 3998 & $(93)$ & 292 & (7) & 1 & & 1 & & 1 & \\
\hline Yes & 467 & (76) & 151 & $(24)$ & 4.4 & $(3.5,5.5)$ & 4.0 & $(3.1,5.1)$ & 1.4 & $(1.0,1.8)$ \\
\hline \multicolumn{11}{|c|}{ Sexual violence in last $12 \mathrm{~m}$} \\
\hline No & 4336 & $(92)$ & 384 & (8) & 1 & & 1 & & 1 & \\
\hline Yes & 127 & $(68)$ & 59 & $(32)$ & 5.2 & $(3.8,7.3)$ & 4.5 & $(3.1,6.5)$ & 1.5 & $(1.0,2.2)$ \\
\hline
\end{tabular}

Moderate or severe anxiety on GAD-7

Economic abuse

$\begin{array}{lcccccccccc}\text { No } & 3505 & (97) & 101 & (3) & 1 & & 1 & & 1 \\ \text { Yes } & 1102 & (85) & 198 & (15) & 6.2 & (4.6,8.5) & 4.8 & (3.4,6.6) & 2.7 & (1.9,3.8) \\ \text { Emotional violence in last } 12 \mathrm{~m} & & & & & & & \\ \text { No } & 3843 & (97) & 136 & (3) & 1 & & 1 & & 1 \\ \text { Yes } & 764 & (82) & 163 & (18) & 6.0 & (4.6,7.9) & 5.5 & (4.1,7.3) & 2.7 & (1.8,4.0)\end{array}$

Physical violence in last $12 \mathrm{~m}$

$\begin{array}{llllllllll}\text { No } & 4099 & (96) & 189 & (4) & 1 & & 1 & & 1 \\ \text { Yes } & 508 & (82) & 110 & (18) & 4.7 & (3.5,6.2) & 4.4 & (3.2,6.1) & 1.4 \\ \text { Sexual violence in last } 12 \mathrm{~m} & & & & & & & & \\ \text { No } & 4465 & (95) & 255 & (5) & 1 & & 1 & & 1 \\ \text { Yes } & 142 & (76) & 44 & (24) & 5.4 & (3.7,7.9) & 4.9 & (3.1,7.8) & 1.6\end{array}$

\section{Suicidal thoughts or action in last $\mathbf{1 2}$ months}

Economic abuse

\begin{tabular}{|c|c|c|c|c|c|c|c|c|c|c|}
\hline No & 3495 & (97) & 111 & (3) & 1 & & 1 & & 1 & \\
\hline Yes & 1097 & (84) & 203 & 16) & 5.8 & $(4.5,7.5)$ & 4.9 & $(3.7,6.4)$ & 2.2 & $(1.5,3.1)$ \\
\hline
\end{tabular}

Emotional violence in last $12 \mathrm{~m}$

$\begin{array}{lllllllllll}\text { No } & 3851 & (97) & 128 & (3) & 1 & & 1 & & 1 & \\ \text { Yes } & 741 & (80) & 186 & (20) & 7.5 & (6.0,9.5) & 6.9 & (5.3,8.9) & 2.8 & (1.8,4.2)\end{array}$

Physical violence in last $12 \mathrm{~m}$

$\begin{array}{lllllllllll}\text { No } & 4121 & (96) & 167 & (4) & 1 & & 1 & & 1 & \\ \text { Yes } & 471 & (76) & 147 & (24) & 7.7 & (5.9,10.1) & 6.7 & (5.0,9.1) & 2.3 & (1.5,3.5)\end{array}$

Sexual violence in last $12 \mathrm{~m}$

\begin{tabular}{lllllllllll} 
No & 4463 & $(95)$ & 257 & $(5)$ & 1 & & 1 & & 1 & \\
Yes & 129 & $(69)$ & 57 & $(31)$ & 7.7 & $(5.4,10.9)$ & 6.2 & $(4.3,9.1)$ & 1.8 & $(1.2,2.6)$ \\
\hline
\end{tabular}

PHQ-9 Patient Health Questionnaire 9-question screen, GAD-7 Generalised Anxiety Disorder 7-question screen, OR crude odds ratio, aOR1 odds ratio adjusted with covariates for respondent age, education, religion, caste, socioeconomic quintile, respondent and husband employment, respondent and husband drug or alcohol use, $a O R 2$ odds ratio adjusted as aOR1 plus covariates for emotional, physical, and sexual violence 


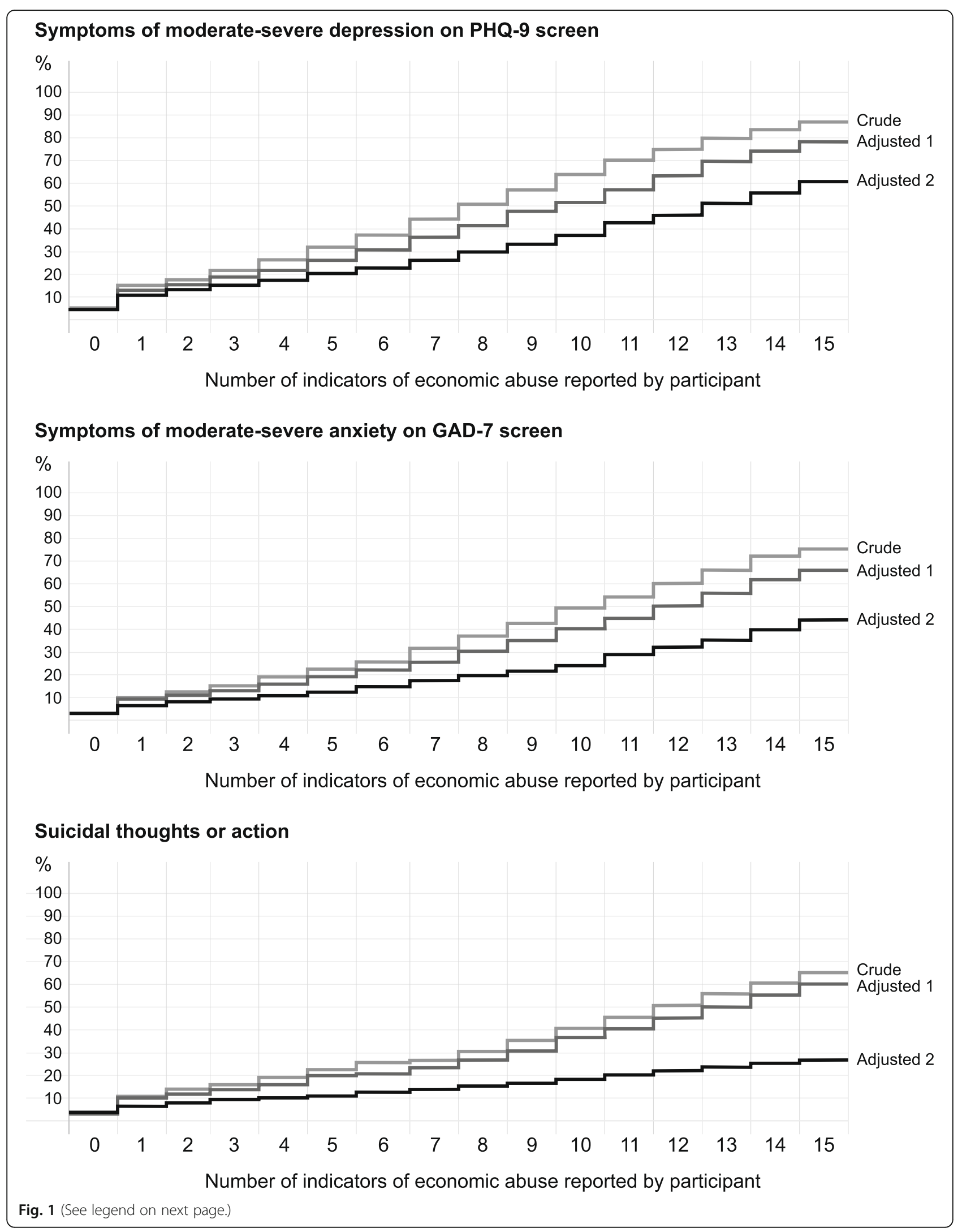


(See figure on previous page.)

Fig. 1 Proportions of women with moderate-severe depression on Patient Health Questionnaire-9 (PHQ-9) screen, moderate-severe anxiety on General Anxiety Disorder (GAD-7) screen, or suicidal thoughts or action, conditional on the experience of 0-15 forms of economic abuse. Adjusted 1: Adjusted with sociodemographic covariates. Adjusted 2: Adjusted with sociodemographic covariates and covariates describing physical, sexual, and emotional violence in the last 12 months

Associations with symptoms of common mental disorders Among a range of forms of domestic violence, economic abuse was the strongest predictor of depressive symptoms. The general prevalence of depression was $5 \%$, of anxiety $3 \%$, and of suicidal ideation $4 \%$. With increasing exposure to a range of forms of economic abuse, these figures increased linearly to a cumulative doubling of risk. The literature supports these findings for depression [50, 72], anxiety [25, 34, 88], and suicidal thoughts [89], which have been linked in Indian studies with marital disharmony, domestic violence, harassment by husbands and in-laws, and dowry disputes [90, 91]. Recent work in Bangladesh suggests that economic abuse may account for at least some of the observed associations of other forms of violence with depressive symptoms [50], and it is important that surveys include questions to identify it [29].

Financial stress can lead to a 'hostile environment' and psychological distress, and further hamper women's selfefficacy and capability for independence. The difficulty of breaking the vicious circle of abuse and dependency has been linked with symptoms of common mental disorders and parental difficulties [34].

\section{Limitations}

We did our survey before we began an intervention to prevent violence against women and girls, and we wanted to make sure we sampled women at greatest risk. We also have a commitment to inclusion, and for both these reasons we focused on women with disability and younger married women. We acknowledge that this might have increased the estimated population prevalence of violence. The cross-sectional nature of the study means that causal inference is difficult. The relationship between domestic violence and mental health is bidirectional and mutually reinforcing, and we do not know how much violence followed mental health concerns in either a woman or her abuser. Our study examined past year experience of domestic violence and current mental health, and we could not investigate whether symptoms of common mental disorder led to subsequent reporting of violence or vice-versa. We were also unable to consider factors such as the mental health of partners and family members.

We limited the analytic dataset to married women in order to maximise the applicability of questions about economic abuse for every respondent. However, questions about property rights, seeking employment, and being coerced to hand over income might not have applied to women who had not tried to gain property, jobs, or income. The denominator includes both women who could have encountered the abuse and women who were not in a situation in which it could arise. We think this is a conservative approach in that it tends to reduce rather than increase the estimated prevalence of obstructions to entitlements.

\section{Conclusion}

After more than four decades of research on domestic violence, the burden of economic abuse is becoming clear, although much of the literature comes from high-income countries and women seeking institutional help. Our study provides empirical support for the idea that more subtle forms of domestic violence - such as economic and emotional violence - are at least as harmful to mental health as physical violence. Our study provides evidence that economic abuse is at least as prevalent as physical and emotional abuse that does not happen in isolation but, is part of the constellation of violence against women, and that strongly associated with mental health. Economic abuse and mental health are well recognised issues in India, and the 2005 Prevention of Violence against Women and Girls Act the 2017 National Mental Health Policy are important policy interventions. There is, however, a need to link the two issues. Institutional responses to economic abuse of women are based on limited knowledge of its prevalence, severity, and outcomes and its recognition by care and support providers is essential. Also important is the fact that survivors of economic violence often do not identify it as abuse. We need to create awareness of how abusers exert control over survivors, including efforts to control, exploit, or sabotage employment. Public sector economic development programs should prioritise mechanisms to prevent economic abuse associated with employment and income generation programmes.

\footnotetext{
Acknowledgments

We are grateful to the women and community guardians who agreed to contribute to the study. We thank the team of investigators who collected data in challenging conditions, Miheeka Vast and Manju Singh for supervising the field investigation team, Unnati Machchhar and Shilpa Adelkar for their supervision of the intervention programme, Gauri Savkur for contributing to investigator training, Bhaskar Kakad for investigator support, Archana Bagra and Vibhavari Bali for financial and human resources management, and Vanessa D'Souza and Shanti Pantvaidya for leadership at SNEHA.
} 


\section{Authors' contributions}

SK, ND, and DO conceived and designed the work. SK and AG designed the data collection materials. SK managed the acquisition of data under the guidance of ND and DO. ND was responsible for the management of the project in which data were collected, and ND and DO acquired funding. SK did the analysis with help from LG and MS. SK interpreted the data and wrote the first draft, and ND, MS, LG, and DO contributed to subsequent drafts. All authors revised the draft critically for intellectual content and approved the final version. The authors agree to be accountable for all aspects of the work in ensuring that questions related to the accuracy or integrity of any part of it are appropriately investigated and resolved.

\section{Funding}

Wellcome Trust 206417. The funder had no role in study design, data collection and analysis, decision to publish, or preparation of the manuscript.

\section{Availability of data and materials}

Data are available in the Open Science Framework: Osrin, D. (2020, December 9). Economic abuse dataset. Retrieved from osf.io/jk576.

\section{Declarations}

\section{Ethics approval and consent to participate}

The trial in which the data were collected is registered with the Controlled Trials Registry of India (CTRI/2018/02/012047, assigned 21/02/2018) and ISRC TN (ISRCTN84502355, assigned 22/02/2018). Ethical approval was granted by the UCL Research Ethics Committee (3546/003, 27/09/2017) and by PUKAR (Partners for Urban Knowledge, Action, and Research) Institutional Ethics Committee (25/12/2017). We followed WHO guidelines for research on domestic violence against women [92], and on sexual violence [93]. Informed consent was obtained from all participants. Interviewers were trained in Good Clinical Practice for research ethics and participant protection (Scientia Clinical Services, 14th February 2019). They provided a participant information sheet, discussed the nature of the interview and right to withdraw, and obtained signed consent. When survivors disclosed violence, intervention protocols included safety assessment, counselling, liaison with healthcare, police, and legal services, and developing follow-up plans for the survivor and her family (all of these with permission from the survivor).

\section{Consent for publication}

Not applicable.

\section{Competing interests}

The authors declare that they have no conflict of interest.

\section{Author details}

${ }^{1}$ Program on Prevention of Violence Against Women and Children, SNEHA, Mumbai, Maharashtra 400017, India. ${ }^{2}$ School of Health Systems Studies (SHSS), Tata Institute of Social Sciences (TISS), Mumbai, Maharashtra, India. ${ }^{3}$ Institute for Global Health, University College London, London WC1N IEH, UK.

\section{Received: 4 January 2021 Accepted: 21 April 2021}

Published online: 01 May 2021

\section{References}

1. WHO. Global and regional estimates of violence against women: prevalence and health effects of intimate partner violence and non-partner sexual violence. Geneva: World Health Organization; 2013.

2. Campbell JC. Health consequences of intimate partner violence. Lancet. 2002;359(9314):1331-6. https://doi.org/10.1016/S0140-6736(02)08336-8.

3. Antai D, Adaji S. Community-level influences on women's experience of intimate partner violence and terminated pregnancy in Nigeria: a multilevel analysis. BMC Pregnancy Childbirth. 2012;12(1):128. https://doi.org/10.11 86/1471-2393-12-128.

4. Mechanic M, Weaver T, Resick P. Mental health consequences of intimate partner abuse: a multidimensional assessment of four different forms of abuse. Violence Against Women. 2008;14(6):634-54. https://doi.org/10.11 77/1077801208319283.
5. Pico-Alfonso M, Garcia-Linares MI, Celda-Navarro N, Blasco-Ros C, Echeburúa E, Martinez M. The impact of physical, psychological, and sexual intimate male partner violence on women's mental health: depressive symptoms, posttraumatic stress disorder, state anxiety, and suicide. J Women's Health. 2006;15(5):599-611. https://doi.org/10.1089/jwh.2006.15.599.

6. WHO. Violence against women prevalence estimates, 2018. In: Global, regional and national prevalence estimates for intimate partner violence against women and global and regional prevalence estimates for nonpartner sexual violence against women. Geneva: World Health Organization, on behalf of the United Nations Inter-Agency Working Group on Violence Against Women Estimation and Data (UNICEF, UNFPA, UNODC, UNSD, UNWomen); 2021

7. WHO. World health statistics 2015. Geneva: World Health Organization; 2015.

8. WHO. Understanding and addressing violence against women: intimate partner violence. Geneva: World Health Organization; 2012.

9. Russo NF, Pirlott A. Gender-based violence: concepts, methods, and findings. Ann N Y Acad Sci. 2006;1087(1):178-205. https://doi.org/10.1196/a nnals.1385.024.

10. Tolman RM. Psychological abuse of women. In: Ammerman RT, Herson M, editors. Wiley series on personality processes. Assessment of family violence: A clinical and legal sourcebook. Hoboken: Wiley; 1992. p. 291-310.

11. Follingstad D, Rutledge L, Berg B, Hause E, Polek D. The role of emotional abuse in physically abusive relationships. J Fam Violence. 1990;5(2):107-20. https://doi.org/10.1007/BF00978514.

12. Kalokhe AS, Potdar RR, Stephenson R, Dunkle KL, Paranjape A, del Rio C, et al. How well does the World Health Organization definition of domestic violence work for India? PLoS One. 2015;10(3):e0120909. https://doi.org/1 0.1371/journal.pone.0120909.

13. WHO. Multi-country study on women's health and domestic violence against women: summary report of initial results on prevalence, health outcomes and women's responses. Geneva: World Health Organization; 2005.

14. Government of India Ministry of Law and Justice. The Protection of Women from Domestic Violence Act, 2005. New Delhi: Legislative Department; 2005.

15. Johnson IM, Sigler RT. Community attitudes: a study of definitions and punishment of spouse abusers and child abusers. J Crim Just. 1995;23(5): 477-87. https://doi.org/10.1016/0047-2352(95)00033-M.

16. Postmus JL, Hoge GL, Breckenridge J, Sharp-Jeffs N, Chung D. Economic abuse as an invisible form of domestic violence: a multicountry review. Trauma Violence Abuse. 2020;21(2):261-83. https://doi.org/10.1177/152483 8018764160.

17. Gibbs A, Dunkle K, Jewkes R. Emotional and economic intimate partner violence as key drivers of depression and suicidal ideation: a cross-sectional study among young women in informal settlements in South Africa. PLOS One. 2018;13(4):e0194885. https://doi.org/10.1371/journal.pone.0194885.

18. Huang C-C, Postmus JL, Vikse JH, Wang L-R. Economic abuse, physical violence, and union formation. Child Youth Serv Rev. 2013;35(5):780-6. https://doi.org/10.1016/j.childyouth.2013.01.020.

19. Stylianou AM, Postmus $J$, MCMahon S. Measuring abusive behaviors: is economic abuse a unique form of abuse? J Interpers Violence. 2013;28(16): 3186-204. https://doi.org/10.1177/0886260513496904.

20. Stark E. Interpersonal violence. Coercive control: how men entrap women in personal life. Oxford: Oxford University Press; 2007.

21. Postmus JL, Plummer SB, McMahon S, Murshid NS. Kim: understanding economic abuse in the lives of survivors. J Interpers Violence. 2012;27(3): 411-30. https://doi.org/10.1177/0886260511421669.

22. Outlaw M. No one type of intimate partner abuse: exploring physical and non-physical abuse among intimate partners. J Fam Violence. 2009;24(4): 263-72. https://doi.org/10.1007/s10896-009-9228-5.

23. Postmus JL, Plummer SB, Stylianou AM. Measuring economic abuse in the lives of survivors: revising the scale of economic abuse. Violence Against Women. 2016;22(6):692-703. https://doi.org/10.1177/1077801215610012.

24. Vyas $P$, Watts $C$. How does economic empowerment affect women's risk of intimate partner violence in low and middle income countries? A systematic review of published evidence. J Int Dev. 2009;21(5):577-602. https://doi.org/10.1002/jid.1500.

25. Antai D, Oke A, Braithwaite P, Lopez GB. The effect of economic, physical, and psychological abuse on mental health: a population-based study of women in the Philippines. Int J Fam Med. 2014:2014:852317. 
26. Fawole Ol. Economic violence to women and girls: is it receiving the necessary attention? Trauma Violence Abuse. 2008;9(3):167-77. https://doi. org/10.1177/1524838008319255.

27. Sanders CK, Schnabel M. Organizing for economic empowerment of battered women: women's savings accounts. J Community Pract. 2006;14(3): 47-68. https://doi.org/10.1300/J125v14n03_04.

28. Strube MJ. The decision to leave an abusive relationship: empirical evidence and theoretical issues. Psychol Bull. 1988;104(2):236-50. https://doi.org/10.1 037/0033-2909.104.2.236

29. Yount KM, Cheong YF, Miedema S, Naved RT. Development and validation of the economic coercion scale 36 (ECS-36) in rural Bangladesh. J Interpers Violence. 2021:886260520987812. Online ahead of print.

30. Burczycka M, Conroy S. Family violence in Canada: a statistical profile, 2016: Statistics Canada. Ottawa: Minister of Industry; 2018.

31. Ansara DL, Hindin MJ. Exploring gender differences in the patterns of intimate partner violence in Canada: a latent class approach. J Epidemiol Community Health. 2010;64(10):849-54. https:/doi.org/10.1136/jech.2009.095208.

32. Kutin J, Russell R, Reid M. Economic abuse between intimate partners in Australia: prevalence, health status, disability and financial stress. Aust N Z J Public Health. 2017;41(3):269-74. https://doi.org/10.1111/1753-64 05.12651 .

33. Voth Schrag RJ. Economic abuse and later material hardship: is depression a mediator? Affilia. 2015;30(3):341-51. https://doi.org/10.1177/0886109914 541118

34. Postmus JL, Huang CC, Stylianou AM. The impact of physical and economic abuse on maternal mental health and parenting. Child Youth Serv Rev. 2012;34(9):1922-8. https://doi.org/10.1016/j.childyouth.2012.06.005

35. Sharp-Jeffs N. Money matters: research into the extent and nature of financial abuse within intimate relationships in the UK. London: Cooperative Bank; 2015.

36. Antai D, Antai J, Anthony SD. The relationship between socio-economic inequalities, intimate partner violence and economic abuse: a national study of women in the Philippines. Global Public Health. 2014;9(7):808-26. https:// doi.org/10.1080/17441692.2014.917195.

37. Yount KM, Krause KH, VanderEnde KE. Economic coercion and partner violence against wives in Vietnam: a unified framework? J Interpers Violence. 2016;31(20):3307-31. https://doi.org/10.1177/0886260515584350.

38. Haj-Yahia MM. The incidence of wife abuse and battering and some sociodemographic correlates as revealed by two national surveys in Palestinian society. J Fam Violence. 2000;15(4):347-74. https://doi.org/10.1 023/A:1007554229592.

39. Vyas P. Reconceptualizing domestic violence in India: economic abuse and the need for broad statutory interpretation to promote women's fundamental rights. Mich J Gend Law. 2006;13:177.

40. Nadda A, Malik JS, Rohilla R, Chahal S, Chayal V, Arora V. Study of domestic violence among currently married females of Haryana, India. Indian J Psychol Med. 2018;40(6):534-9. https://doi.org/10.4103/IJPSYM.IJPSYM_62_18.

41. Shah SH, Rajani K, Kataria L, Trivedi A, Patel S, Mehta K. Perception and prevalence of domestic violence in the study population. Ind Psychiatr J. 2012;21(2):137-43. https://doi.org/10.4103/0972-6748.119624.

42. Chaudhary A, Girdhar S, Soni RK. Epidemiological correlates of domestic violence in married women in urban area of Ludhiana, Punjab, India. Internet J Health. 2009;9(1):215-7.

43. Yugantar Education Society. A study of nature, extent, incidence and impact of domestic violence against women in the states of Andhra Pradesh, Chhattisgarh, Gujrat, Madhya Pradesh and Maharashtra. Nagpur: Yugantar Education Society; 2003.

44. Logan J, Hall J, Karch D. Suicide categories by patterns of known risk factors: a latent class analysis. Arch Gen Psychiatry. 2011;68(9):935-41. https://doi. org/10.1001/archgenpsychiatry.2011.85.

45. Vachher AS, Sharma AK. Domestic violence against women and their mental health status in a colony in Delhi. Indian J Community Med. 2010; 35(3):403-5. https://doi.org/10.4103/0970-0218.69266

46. Kumar S, Jeyaseelan L, Suresh S, Ahuja RC. Domestic violence and its mental health correlates in Indian women. Br J Psychiatry. 2005;187(1):62-7. https:// doi.org/10.1192/bjp.187.1.62.

47. Patel VI, Rodrigues M, DeSouza N. Gender, poverty, and postnatal depression: a study of mothers in Goa, India. Am J Psychiatr. 2002;159:43-7.

48. Rodrigues M, Patel V, Jaswal S, De Souza N. Listening to mothers: qualitative studies on motherhood and depression from Goa, India. Soc Sci Med. 2003: 57(10):1797-806. https://doi.org/10.1016/S0277-9536(03)00062-5.
49. Pereira B, Andrew G, Pednekar S, Pai R, Pelto P, Patel V. The explanatory models of depression in low income countries: listening to women in India. J Affect Disord. 2007;102(1-3):209-18. https://doi.org/1 0.1016/j.jad.2006.09.025

50. Khan Z, Cheong YF, Miedema SS, Naved RT, Yount KM. Women's experiences of economic coercion and depressive symptoms in Matlab, Bangladesh. SSM Popul Health. 2020;12:100641. https://doi.org/10.1016/j. ssmph.2020.100641.

51. Tenkorang EY, Owusu AY. Does economic abuse affect the health outcomes of women in Ghana? Health Educ Behav. 2019;46(2):340-8. https://doi.org/1 $0.1177 / 1090198118806970$.

52. Devries KM, Mak JY, Bacchus LJ, Child JC, Falder G, Petzold M, et al. Intimate partner violence and incident depressive symptoms and suicide attempts: a systematic review of longitudinal studies. PLoS Med. 2013;10(5):e1001439. https://doi.org/10.1371/journal.pmed.1001439.

53. Jewkes R. Emotional abuse: a neglected dimension of partner violence. Lancet. 2010;376(9744):851-2. https://doi.org/10.1016/S0140-6736(10)61079-3.

54. UN-HABITAT. The challenge of slums: global report on human settlements, 2003. London \& Sterling: Earthscan; 2003.

55. Chandramouli C. Housing stock, amenities and assets in slums-Census 2011. New Delhi: Office of the Registrar General and Census Commissioner; 2011.

56. Daruwalla N, Machchhar U, Pantvaidya S, D'Souza V, Gram L, Copas A, et al. Community interventions to prevent violence against women and girls in informal settlements in Mumbai: the SNEHA-TARA pragmatic cluster randomised controlled trial. Trials. 2019;20(1):743. https://doi.org/10.1186/s13063-019-3817-2.

57. Ellsberg $M$, Heise L. Researching violence against women: practical guidelines for researchers and activists. Washington DC: World Health Organization; PATH; 2005.

58. Daruwalla N, Kanougiya S, Gupta A, Gram L, Osrin D. Prevalence of domestic violence against women in informal settlements in Mumbai, India: a crosssectional survey. BMJ Open. 2020;10(12):e042444. https://doi.org/10.1136/ bmjopen-2020-042444.

59. Kroenke K, Spitzer RL, Williams JB. The PHQ-9: validity of a brief depression severity measure. J Gen Intern Med. 2001;16(9):606-13. https://doi.org/10.1 046/j.1525-1497.2001.016009606.x.

60. Löwe B, Decker O, Müller S, Brähler E, Schellberg D, Herzog W, et al. Validation and standardization of the generalized anxiety disorder screener (GAD-7) in the general population. Med Care. 2008;46(3):266-74. https://doi. org/10.1097/MLR.0b013e318160d093.

61. Spitzer RL, Kroenke K, Williams JBW, Löwe B. A brief measure for assessing generalized anxiety disorder: the GAD-7. Arch Intern Med. 2006;166(10): 1092-7. https://doi.org/10.1001/archinte.166.10.1092.

62. Kochhar PH, Rajadhyaksha SS, Suvarna VR. Translation and validation of brief patient health questionnaire against DSM IV as a tool to diagnose major depressive disorder in Indian patients. J Postgrad Med. 2007:53(2):102-7. https://doi.org/10.4103/0022-3859.32209.

63. Ganguly S, Samanta M, Roy P, Chatterjee S, Kaplan DW, Basu B. Patient health questionnaire-9 as an effective tool for screening of depression among Indian adolescents. J Adolesc Health. 2013;52(5):546-51. https://doi. org/10.1016/j.jadohealth.2012.09.012.

64. Gothwal VK, Bagga DK, Sumalini R. Rasch validation of the PHQ-9 in people with visual impairment in South India. J Affect Disord. 2014;167:171-7. https://doi.org/10.1016/j.jad.2014.06.019.

65. Indu PS, Anilkumar TV, Vijayakumar K, Kumar KA, Sarma PS, Remadevi S, et al. Reliability and validity of PHQ-9 when administered by health workers for depression screening among women in primary care. Asian J Psychiatr. 2018;37:10-4. https://doi.org/10.1016/j.ajp.2018.07.021.

66. Mughal AY, Devadas J, Ardman E, Levis B, Go VF, Gaynes BN. A systematic review of validated screening tools for anxiety disorders and PTSD in low to middle income countries. BMC Psychiatry. 2020;20(1):338. https://doi.org/1 0.1186/s12888-020-02753-3.

67. Löwe B, Spitzer RL, Gräfe K, Kroenke K, Quenter A, Zipfel S, et al. Comparative validity of three screening questionnaires for DSM-IV depressive disorders and physicians' diagnoses. J Affect Disord. 2004;78(2): 131-40. https://doi.org/10.1016/S0165-0327(02)00237-9.

68. McKinnon B, Gariépy G, Sentenac M, Elgar FJ. Adolescent suicidal behaviours in 32 low-and middle-income countries. Bull WHO. 2016;94:340.

69. Vyas P, Kumaranayake L. Constructing socio-economic status indices: how to use principal components analysis. Health Policy Plan. 2006;21(6):459-68. https://doi.org/10.1093/heapol/czl029. 
70. Filmer D, Pritchett LH. Estimating wealth effects without expenditure data-or tears: an application to educational enrollments in states of India. Demography. 2001;38(1):115-32. https://doi.org/10.1353/dem.2001.0003.

71. Breckenridge J, Walden I, Flax G. Staying home leaving violence evaluation: final report. In: Gendered Violence Research Network. Sydney: University of New South Wales; 2014.

72. Adams AE, Sullivan CM, Bybee D, Greeson MR. Development of the scale of economic abuse. Violence Against Women. 2008;14(5):563-88. https://doi. org/10.1177/1077801208315529.

73. Das S, Bapat U, More NS, Alcock G, Joshi W, Pantvaidya S, et al. Intimate partner violence against women during and after pregnancy: a crosssectional study in Mumbai slums. BMC Public Health. 2013;13(1):817. https:// doi.org/10.1186/1471-2458-13-817.

74. Deering KN, Bhattacharjee P, Mohan HL, Bradley J, Shannon K, Boily M-C, et al. Violence and HIV risk among female sex workers in southern India. Sex Transm Dis. 2013;40(2):168-74. https://doi.org/10.1097/OLQ.0b013e31827df174.

75. Mahapatro M, Gupta RN, Gupta V. The risk factor of domestic violence in India. Indian J Community Med. 2012;37(3):153-7. https://doi.org/10.4103/ 0970-0218.99912.

76. Mogford E. When status hurts: dimensions of women's status and domestic abuse in rural northern India. Violence Against Women. 2011;17(7):835-57. https://doi.org/10.1177/1077801211412545.

77. Pandey GK, Dutt D, Banerjee B. Partner and relationship factors in domestic violence: perspectives of women from a slum in Calcutta, India. J Interpers Violence. 2009;24(7):1175-91. https://doi.org/10.1177/0886260508322186.

78. Murthy RS. National mental health survey of India 2015-2016. Indian J Psychiatry. 2017;59(1):21-6. https://doi.org/10.4103/psychiatry.IndianJPsychiatry_102_17.

79. Reddy VM, Chandrashekar CR. Prevalence of mental and behavioural disorders in India: a meta-analysis. Indian J Psychiatry. 1998:40:149.

80. Basu S. She comes to take her rights: Indian women, property, and propriety. Herndon: SUNY Press; 1999

81. Wadley S. No longer a wife: widows in rural North India. In: Harlan L, Courtright $P$, editors. From the margins of Hindu marriage: Essays on gender, religion and culture. Oxford: Oxford University Press; 1995. p. 92-118.

82. Dalal K. Does economic empowerment protect women from intimate partner violence? J Inj Violence Res. 2011;3(1):35-44. https://doi.org/10.5249/ jivr.v3i1.76.

83. Hindin MJ, Adair LS. Who's at risk? Factors associated with intimate partner violence in the Philippines. Soc Sci Med. 2002;55(8):1385-99. https://doi. org/10.1016/S0277-9536(01)00273-8

84. Riger S, Krieglstein M. The impact of welfare reform on men's violence against women. Am J Community Psychol. 2000;28(5):631-47. https://doi. org/10.1023/A:1005193603532.

85. Brush LD. Effects of work on hitting and hurting. Violence Against Women. 2003;9(10):1213-30. https://doi.org/10.1177/1077801203255848.

86. Anderson KL. Perpetrator or victim? Relationships between intimate partner violence and well-being. J Marriage Fam. 2002;64(4):851-63. https://doi. org/10.1111/j.1741-3737.2002.00851.x.

87. Weinsheimer RL, Schermer CR, Malcoe LH, Balduf LM, Bloomfield LA. Severe intimate partner violence and alcohol use among female trauma patients. J Trauma Acute Care Surg. 2005;58(1):22-9. https://doi.org/10.1097/01.TA. 0000151180.77168.A6.

88. Devries KM, Watts C, Yoshihama M, Kiss L, Schraiber LB, Deyessa N, et al. Violence against women is strongly associated with suicide attempts: evidence from the WHO multi-country study on women's health and domestic violence against women. Soc Sci Med. 2011;73(1):79-86. https:// doi.org/10.1016/j.socscimed.2011.05.006.

89. Ellsberg M, Jansen HA, Heise L, Watts CH, Garcia-Moreno C. Intimate partner violence and women's physical and mental health in the WHO multi-country study on women's health and domestic violence: an observational study. Lancet. 2008;371(9619):1165-72. https://doi.org/10.1016/S0140-6736(08)60522-X.

90. Gajalakshmi V, Peto R. Suicide rates in rural Tamil Nadu, South India: verbal autopsy of 39000 deaths in 1997-98. Int J Epidemiol. 2007;36(1):203-7. https://doi.org/10.1093/ije/dyl308.

91. Gururaj G, Isaac MK, Subbakrishna D, Ranjani R. Risk factors for completed suicides: a case-control study from Bangalore, India. Inj Control Saf Promot. 2004;11(3):183-91. https://doi.org/10.1080/156609704/233/289706.

92. WHO. Putting women first: Ethical and safety recommendations for research on domestic violence against women. Geneva: World Health Organization; 2001.
93. Jewkes R, Dartnall E and Sikweyiya Y. Ethical and Safety Recommendations for Research on Perpetration of Sexual Violence. Pretoria: Sexual Violence Research Initiative, Medical Research Council; 2012.

\section{Publisher's Note}

Springer Nature remains neutral with regard to jurisdictional claims in published maps and institutional affiliations.
Ready to submit your research? Choose BMC and benefit from:

- fast, convenient online submission

- thorough peer review by experienced researchers in your field

- rapid publication on acceptance

- support for research data, including large and complex data types

- gold Open Access which fosters wider collaboration and increased citations

- maximum visibility for your research: over $100 \mathrm{M}$ website views per year

At BMC, research is always in progress.

Learn more biomedcentral.com/submissions 